\title{
Correction to: Irreversible Electroporation For Hepatocellular Carcinoma: Longer-Term Outcomes At A Single Centre
}

\author{
E. Freeman ${ }^{1}$ (1) W. Cheung ${ }^{2} \cdot$ H. Kavnoudias ${ }^{2} \cdot$ A. Majeed $^{1,3} \cdot$ W. Kemp ${ }^{1,3} \cdot$ \\ S. K. Roberts ${ }^{1,3}$
}

Published online: 16 November 2020

(C) Springer Science+Business Media, LLC, part of Springer Nature and the Cardiovascular and Interventional Radiological Society of Europe (CIRSE) 2020

\section{Cardiovasc Intervent Radiol https://doi.org/10.1007/s00270-020-02666-4}

An author was inadvertently omitted from the author list. Helen Kavnoudias should be listed as third author. The added author's name and affiliation are marked by underlines.

E. Freeman ${ }^{1}$, W. Cheung ${ }^{2}$, H. Kavnoudias ${ }^{2}$, A. Majeed $^{1,3}$, W. Kemp ${ }^{1,3}$, S. K. Roberts ${ }^{1,3}$

${ }^{2}$ Department of Radiology, Alfred Hospital, Melbourne, Australia
Author Contributions All authors contributed to the study conception and design. Material preparation, data collection and analysis were performed by Elliot Freeman. The first draft was written by Elliot Freeman and EF, WC, AM, WK, and SKR reviewed earlier versions of the manuscript, with all authors reviewing and approving the final version of the manuscript.

The original article has been corrected.

Publisher's Note Springer Nature remains neutral with regard to jurisdictional claims in published maps and institutional affiliations.

The original article can be found online at https://doi.org/10.1007/ s00270-020-02666-4.

\footnotetext{
S. K. Roberts

s.roberts@alfred.org.au

1 Department of Gastroenterology, Alfred Hospital, Melbourne, Australia

2 Department of Radiology, Alfred Hospital, Melbourne, Australia

3 Department of Medicine, Central Clinical School, Monash University, Melbourne, Australia
} 